\title{
Antimicrobial Properties of the Essential Oil of Juniperus communis (L.) Growing Wild in East Part of Kosovo
}

\author{
${ }^{1}$ Arben Haziri, ${ }^{1}$ Fatmir Faiku, ${ }^{2}$ Arben Mehmeti, ${ }^{1}$ Sevdije Govori, \\ ${ }^{3}$ Sokol Abazi, ${ }^{2}$ Majlinda Daci, ${ }^{2}$ Imer Haziri, ${ }^{1}$ Arlinda Bytyqi-Damoni and ${ }^{3}$ Altin Mele \\ ${ }^{1}$ Department of Chemistry, Faculty of Natural Science, University of Pristina, Prishtine, Kosova \\ ${ }^{2}$ Department of Agriculture, Faculty of Agriculture and Veterinary, University of Pristina, Prishtine, Kosova \\ ${ }^{3}$ Department of Chemistry, Faculty of Natural Science, University of Tirana, Tiranë, Albania
}

Received 2012-03-25, Revised 2013-09-21; Accepted 2013-09-23

\begin{abstract}
Antimicrobial activity and chemical composition of the essential oil of Juniperus communis (L.), originated from east part of Kosova, was investigated. The essential oil from berries of $J$. communis (L.), obtained by hydro-distillation was analyzed by GC and GC-MS. Antimicrobial properties of the essential oil of $J$. communis (L.) are investigated and results are submitted for their activities against Staphylococcus aureus, Escherichia coli, Hafnia alvei and Pseudomonas aeruginosa. Applying the agar disc diffusion technique, we measured diameters of the inhibition zone around discs, which are previously wetted with DMF solution of the essential oil with three different concentrations, 1,3 and $5 \mathrm{mg} \mathrm{mL}^{-1}$. Analysis of the oil resulted in the identification of 41 peaks, representing $96 \%$ of the oil. Berry essential oil composed mainly of monoterpenoids which amounted to $83 \%$, of which $69.4 \%$ was monoterpene hydrocarbons. The main monoterpene hydrocarbons were $\alpha$-pinene $(36.2 \%)$ and $\beta$-myrcene $(21.1 \%)$. The sesquiterpene accounted for about $13.4 \%$ of the total oil composition. Germacrene D $(2.2 \%)$, $\alpha$-cadinol $(1.6 \%)$, $\alpha$-humulene $(1.5 \%)$, spathulenol (1.4\%), epi- $\alpha$-bisabolol $(1.3 \%)$ and germacrene B (1.1\%) were the main constituents of the sesquiterpenes. The inhibition zone depends from concentrations and also from sort of bacteria. The inhibition zones differ from 0-39 $\mathrm{mm}$. The present work presents the chemical composition of the hydrodistilled oil of $J$. communis (L.) from East part of Kosova and the results are compared to those reported in the literature. This study demonstrates the occurrence of $\alpha$-pinene chemotype of $J$. communis (L.) from east part of Kosova. The essential oil of J. communis (L.) growing wild in Kosova, showed moderate to high activities against Staphylococcus aureus, Escherichia coli, Hafnia alvei. Pseudomonas aeruginosa is resistant to the essential oil of J. communis (L.) growing wild in east part of Kosova.
\end{abstract}

Keywords: Juniperus communis (L.), Essential Oil, Antimicrobial Activity, Staphylococcus Aureus, Escherichia Coli, Hafnia Alvei, Pseudomonas Aeruginosa

\section{INTRODUCTION}

Our research group is interested to analyze the chemical profile of essential oils from different medicinal plants Albania (Haziri et al., 2009; 2010). Juniperus communis (L.) is the medicinal plant, which is present in the fields of which are growing wild in the region of Kosova and

Kosova and their fruits and leaves have been used for a long time to treat different disease.

Juniperus communis (L.) belonging to the family Cupressaceae (common name Juniper). Common juniper (Juniperus communis (L.) is a natural evergreen shrub or tree growing in dry uncultivated regions of Asia, Europe, North Africa and North America. The berries (Juniperi Corresponding Author: Arben Haziri, Department of Chemistry, Faculty of Natural Science, University of Pristina, Prishtine, Kosova 
fructus) contain an essential oil having a characteristic aromatic flavor and bitter test. Juniper oil is a natural product which is used in the pharmaceutical and food industries and perfumery, as well as in cosmetics (Leung and Foster, 1996). Juniper berries have long been used as flavoring agents in foods and alcoholic beverages such as gin. Certain spirits (gin) are made by distillation from fermented juniper berries (Maarse, 1991).

Changes in the composition of an essential oil can be caused by environmental factors, such as the soil or climate in which the plants are grown and by different harvesting methods or distillation techniques. In the last years a number of publications have reported the composition of the berries and leaves essential oil of the Juniperus species (Kallio and Junger-Mannermaa, 1989; Chatzopoulou and Katsiotis, 1993a; 1993b; Koukos and Papadopoulou, 1997; Ochocka et al., 1997; Angioni et al., 2003; Milojevic et al., 2008; Orav et al., 2010). The chemical nature of juniper essential oil differs depending on its origin. As we seen from the literature, the amount of some components may significantly vary. In the studies of the essential oil of juniper, it was established that the pharmacological features are derived from its constituents.

The aim of this study was to investigate the antimicrobial activity and chemical composition of the berries essential oil of Juniperus communis (L.) grown wild in east part of Kosova and the results are compared to those reported in the literature.

\section{MATERIALS AND METHODS}

The plant material (berries sample) of Juniperus communis (L.), growing wild in east part of Kosova (Kamenica locality), were collected in December 2010. They were identified at the Department of Plant Protection, Faculty of Agriculture and Veterinary, Prishtina University. Voucher specimens were deposited in the Herbarium of the Department of Plant Protection, University of Prishtina (Number AH3). Berries were cleaned from impurities and dried at room temperature $\left(22^{\circ} \mathrm{C}\right)$. The berries were then individually crushed. The dried material was powdered in an electric grinder. The berries of essential oil of Juniperus communis (L.) was extracted with steam distillation of air dried fruits for $4 \mathrm{~h}$. The prepared volatile oils were dehydrated over anhydrous sodium sulphate and stored in refrigerator until analyzed. The yield was $1.23 \%(\mathrm{v} / \mathrm{w})$.

The analysis of essential oil was carried out by GC and GC-MS. The HP 5890 II chromatograph equipped with an FID detector and capillary column DP-5MS (30 $\mathrm{m} \times 0.25 \mathrm{~mm}$ ) was used for quantitative analysis. The GC oven temperature was set at $60^{\circ} \mathrm{C}$ for $3 \mathrm{~min}$, then programmed to $200^{\circ} \mathrm{C}$ at a rate of $3^{\circ} \mathrm{C} / \mathrm{min}$, then programmed from 200 to $240^{\circ} \mathrm{C}$ at a rate of $6^{\circ} \mathrm{C} / \mathrm{min}$. Helium was the carrier gas $\left(1 \mathrm{~mL} \mathrm{~min}^{-1}\right)$. Oil was diluted with acetone $(1 / 100$ in acetone, v/v) and $1 \mu \mathrm{L}$ of diluted sample was injected manually. The percentage composition of the essential oil was computed from GC peak areas without correction factors.

Analysis by GC-MS was performed using a chromatograph HP 5890 II GC interfaced to a HP 5972 mass spectrometer (ionization voltage $70 \mathrm{eV}$ ). The column was a fused silica capillary DP-5MS (5\% phenylmethylpolysyloxane, $30 \mathrm{~m} \times 0.25 \mathrm{~mm})$. The oven temperature program was $60^{\circ} \mathrm{C}$ for $2 \mathrm{~min}$, then from 60 to $200^{\circ} \mathrm{C}$ at a rate of $3^{\circ} \mathrm{C} / \mathrm{min}$, held for $15 \mathrm{~min}$. He was the carrier gas $\left(1 \mathrm{~mL} \mathrm{~min}^{-1}\right)$. The temperatures of injector and detector were 200 and $280^{\circ} \mathrm{C}$, respectively. Scan mass range was 40-450.

Qualitative analysis was based on a comparison of retention times and indexes on both columns and mass spectra with corresponding data in the literature (Adams, 2001) and computer mass spectra libraries (Wiley and NBS 75K).

The antimicrobial activity of the essential oil of $J$. communis (L.) was determined by Agar disc diffusion technique. Essential oil samples were tested in vitro against bacterial strains; Staphylococcus aureus, Escherichia coli, Hafnia alvei and Pseudomonas aeruginosa. Discs are previously wetted with DMF solution of the essential oil with three different concentrations, 1,3 and $5 \mathrm{mg} \mathrm{mL}^{-1}$. The samples were incubated at $37^{\circ} \mathrm{C}$ during $24 \mathrm{hrs}$ and the inhibition zones were measured.

\section{RESULTS}

The essential oil from aerial parts of Juniperus communis (L.), obtained by hydro-distillation was analyzed by GC and GC-MS. The identified compounds and their percentage are given in Table 1-4. The oil yield was $1.23 \%(\mathrm{v} / \mathrm{w})$. Analysis of the oil resulted in the identification of 41 peaks, representing $96 \%$ of the oil.

Continuation to our study, we examined the antimicrobial activity of the essential oil of $J$. communis (L.). Our investigation is directed toward their activity against Staphylococcus aureus, Escherichia coli, Hafnia alvei and Pseudomonas aeruginos. Applying the Agar disc diffusion technique we measured diameters of the inhibition zone around discs which are previously wetted with DMF solution of the essential oil. The antimicrobial activity of the essential oil of $J$. communis (L.) was tested at three different concentrations 1, 3 and $5 \mathrm{mg} \mathrm{mL}^{-1}$ (Table 5). 
Arben Haziri et al. / American Journal of Pharmacology and Toxicology 8 (3): 128-133, 2013

Table 1. Monoterpene hydrocarbons in Juniperus communis (L.) essential oil (KI: Kovat's Index relative to $\mathrm{C}_{9}-\mathrm{C}_{24}$ alkanes on the DB-5 column)

\begin{tabular}{lcr}
\hline Hydrocarbons monoterpene & KI & $(\%)$ \\
\hline$\alpha$-thujene & 915 & 0.2 \\
$\alpha$-pinene & 931 & 36.2 \\
(-) camphene & 939 & 0.7 \\
dihydrosabinene & 946 & 1.3 \\
sabinen & 967 & 2.4 \\
$\beta$-pinene & 970 & 3.2 \\
$\beta$-myrcen & 989 & 21.1 \\
$\alpha$-phellandrene & 1001 & 0.6 \\
$\gamma$-3-carene & 1004 & 0.3 \\
$\alpha$-terpinene & 1010 & 0.8 \\
limonene & 1019 & 1.8 \\
terpinolene & 1084 & 0.5 \\
p-cymene & 1086 & 0.3 \\
\hline
\end{tabular}

Table 2. Oxygenated monoterpenes in Juniperus communis (L.) essential oil (KI: Kovat's Index relative to $\mathrm{C}_{9}-\mathrm{C}_{24}$ alkanes on the DB-5 column)

\begin{tabular}{lll}
\hline Oxygenated monoterpenes & KI & $\mathbf{( \% )}$ \\
\hline a-campholenol & 1119 & 1.6 \\
trans-pinocarveol & 1127 & 2.4 \\
3-methyl-2-butenyl valeriate & 1134 & 0.4 \\
cis-verbenol & 1139 & 0.9 \\
camphene hydrate & 1154 & 0.2 \\
isoborneol & 1156 & 0.2 \\
p-mentha-1,5-dien-8-ol & 1162 & 0.9 \\
terpinen-4-ol & 1174 & 2.1 \\
p-cymen-8-ol & 1179 & 1.2 \\
a-terpineol & 1183 & 0.1 \\
myrtenal & 1189 & 0.9 \\
myrtenol & 1196 & 0.1 \\
verbenone & 1201 & 2.1 \\
bornyl acetate & 1284 & 0.5 \\
\hline
\end{tabular}

Table 3. Sesquiterpene hydrocarbons in Juniperus communis (L.) essential oil (KI: Kovat's Index relative to $\mathrm{C}_{9}-\mathrm{C}_{24}$ alkanes on the DB-5 column

\begin{tabular}{lll}
\hline Sesquiterpene hydrocarbons & KI & $(\%)$ \\
\hline E)- $\beta$-caryophyllene & 1415 & 0.9 \\
$\alpha$-humulene & 1445 & 1.5 \\
(E)- $\beta$-farnesene & 1456 & 0.2 \\
germacrene D & 1470 & 2.2 \\
$\alpha$-amorphene & 1476 & 0.3 \\
$\gamma$-cadinene & 1506 & 0.7 \\
$\delta$-cadinene & 1515 & 0.8 \\
germacrene B & 1542 & 1.1 \\
\hline
\end{tabular}

Table 4. Oxygenated sesquiterpenes in Juniperus communis (L.) essential oil (KI: Kovat's Index relative to $\mathrm{C}_{9}-\mathrm{C}_{24}$ alkanes on the DB-5 column)

\begin{tabular}{lll}
\hline Oxygenated sesquiterpene & KI & $(\%)$ \\
\hline spathulenol & 1559 & 1.4 \\
germacren D-4-ol & 1563 & 0.9 \\
$\delta$-cadinol & 1632 & 0.5 \\
$\alpha$-cadinol & 1648 & 1.6 \\
epi- $\alpha$-bisabolol & 1681 & 1.3 \\
\hline
\end{tabular}

Table 5. The diameter of the inhibition zone (in $\mathrm{mm}$ )

\begin{tabular}{|c|c|c|c|}
\hline & \multicolumn{3}{|c|}{ Concentration } \\
\hline & $1 \mathrm{mg} \mathrm{L}^{-1}$ & $3 \mathrm{mg} \mathrm{L}^{-1}$ & $5 \mathrm{mg} \mathrm{L}^{-1}$ \\
\hline $\begin{array}{l}\text { S. aureus } \\
\text { ATCC® } 25923\end{array}$ & 16 & 23 & 29 \\
\hline $\begin{array}{l}\text { E. coli } \\
\text { ATCC } ₫ 25922\end{array}$ & 25 & 28 & 39 \\
\hline $\begin{array}{l}\text { H. alvei } \\
\text { PTCC }(2005\end{array}$ & 9 & 12 & 13 \\
\hline $\begin{array}{l}\text { P. aeruginosa } \\
\text { ATCC® } 27853\end{array}$ & 0 & 0 & 0 \\
\hline
\end{tabular}

\section{DISCUSSION}

The main components in essential oil of $J$. communis L. were terpenoids $(83 \%)$ and sesquiterpenes $(13.4 \%)$. In the berries essential oil of $J$. communis L. monoterpene hydrocarbons predominated (69.4\%). The main monoterpene hydrocarbons of $J$. communis (L.) from east region of Kosova, were $\alpha$-pinene $(36.2 \%)$ and $\beta$ myrcene $(21.1 \%)$. The predominant minor constituents of monoterpenes hydrocarbons were $\beta$-pinene $(3.2 \%)$, sabinen $(2.4 \%)$, limonene $(1.8 \%)$ and dihydrosabinene $(1.3 \%)$ (Table 1). The amount of the oxygenated monoterpenes in the juniper-berry oil was $13.6 \%$. trans-pinocarveol (2.4\%), terpinen-4-ol (2.1\%), verbenone $(2.1 \%), \alpha$-campholenol $(1.6 \%)$ and $p$ cymen-8-ol (1.2\%) accounted for most of the oxygenated monoterpenes (Table 2). In Fig. 1 are shown the comparison of the percentages of the hydrocarbons and oxygenated monoterpenes.

Berry essential oil contains also the sesquiterpenes which amounted to $13.4 \%$ (Table 3 and 4 ). The sesquiterpene hydrocarbons accounted for about $7.7 \%$ of the total oil composition. Germacrene D (2.2\%), $\alpha$ humulene $(1.5 \%)$ and germacrene $\mathrm{B}(1.1 \%)$ were the most abundant sesquiterpene hydrocarbons in the berry oil (Table 3). The juniper-berry oil contained up to $5.7 \%$ oxygenated sesquiterpene. $\alpha$-cadinol (1.6\%), spathulenol $(1.4 \%)$ and epi- $\alpha$-bisabolol $(1.3 \%)$ were the main constituents of the oxygenated sesquiterpenes (Table 4). In Fig. 2 are shown the comparison of the percentages of the hydrocarbons and oxygenated sesquiterpenes.

The high content of $\alpha$-pinene $(36.2 \%)$ of the oil from the juniper of Kosova region compared well with that of the oil from Greek (27-62\%) $)^{6-8}$, Polish and French (45$80 \%)^{9}$ and Italian $(52.3 \%)^{10}$ juniper. Our oil is in agreement with essential oil of $J$. communis L. from Serbia $^{11}$ in the percentage composition of $\alpha$-pinene $(41.7 \%)$ and myrcene (14.3\%). 


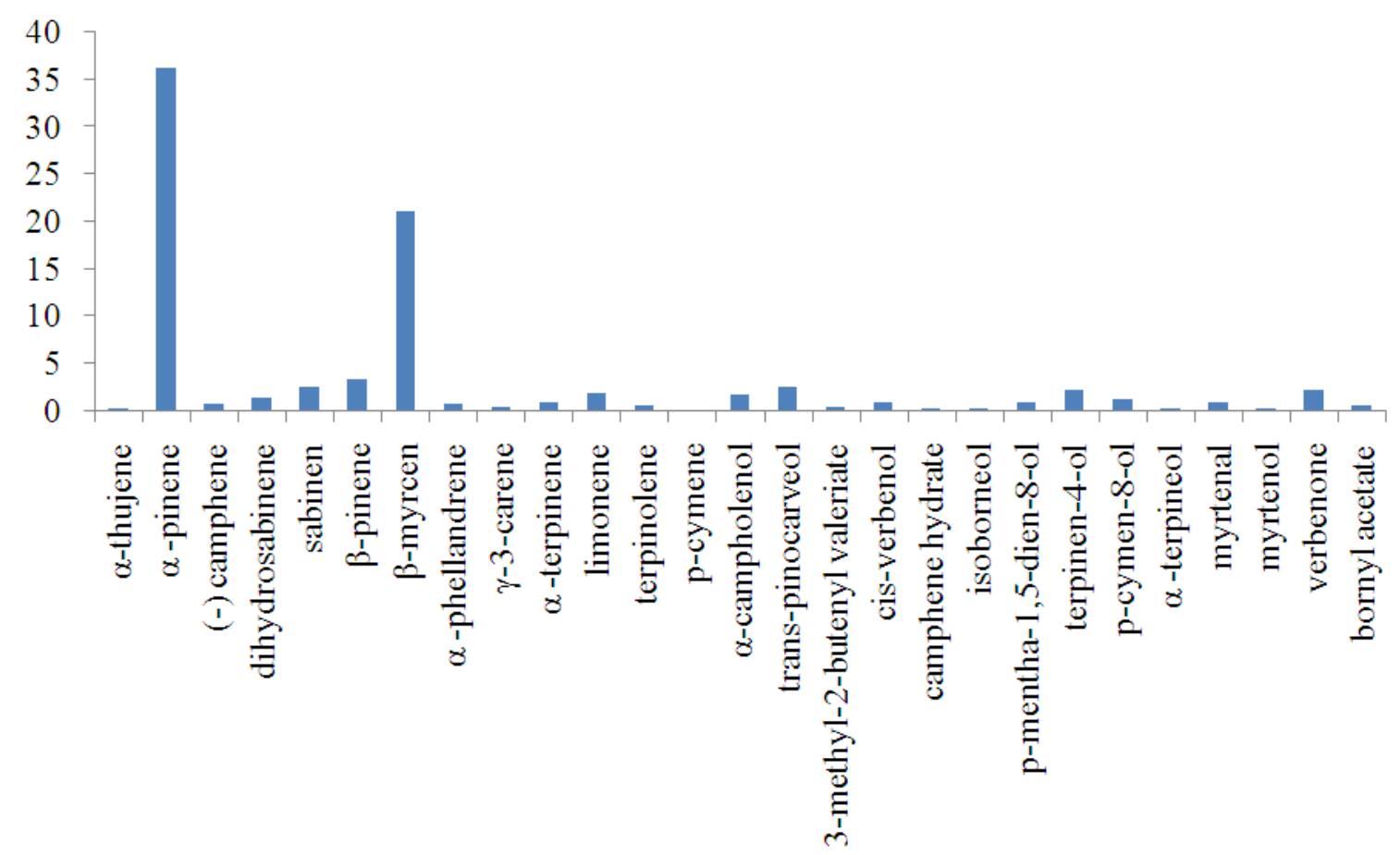

Fig. 1. Percentages comparison of the hydrocarbons and oxygenated monoterpenes in essential oil of J. communis (L.) growing wild in Kosova

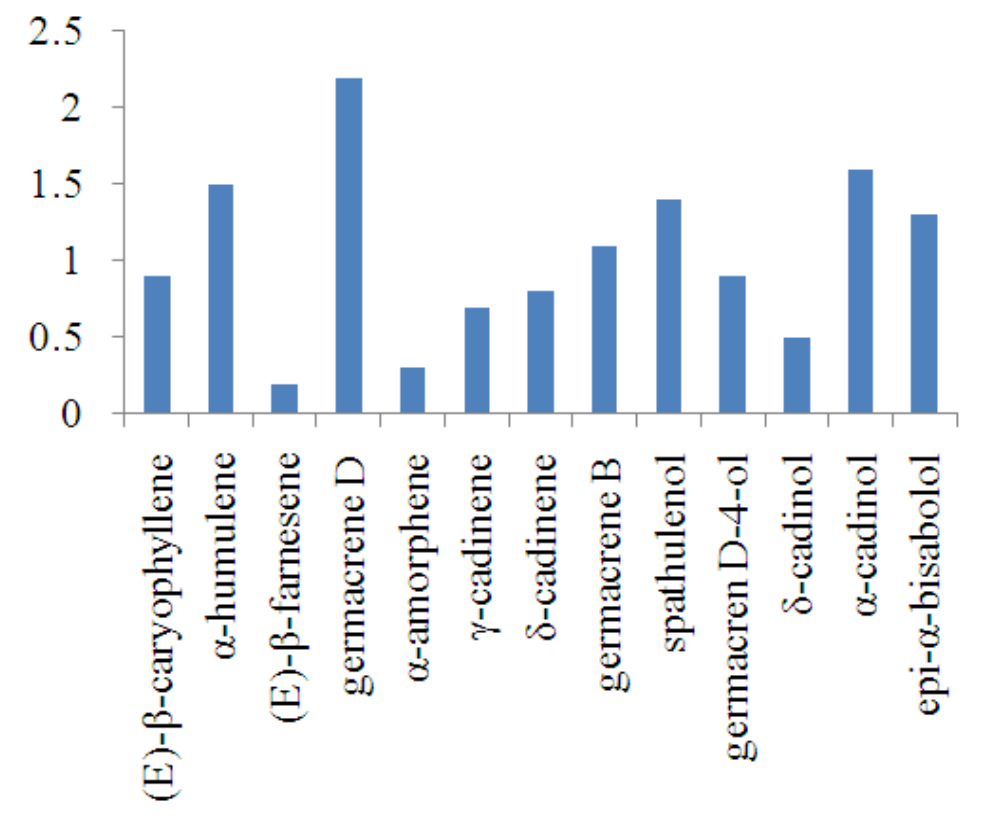

Fig. 2. Percentage comparison of the hydrocarbons and oxygenated sesquiterpene in essential oil of J. communis (L.) growing wild in Kosova 


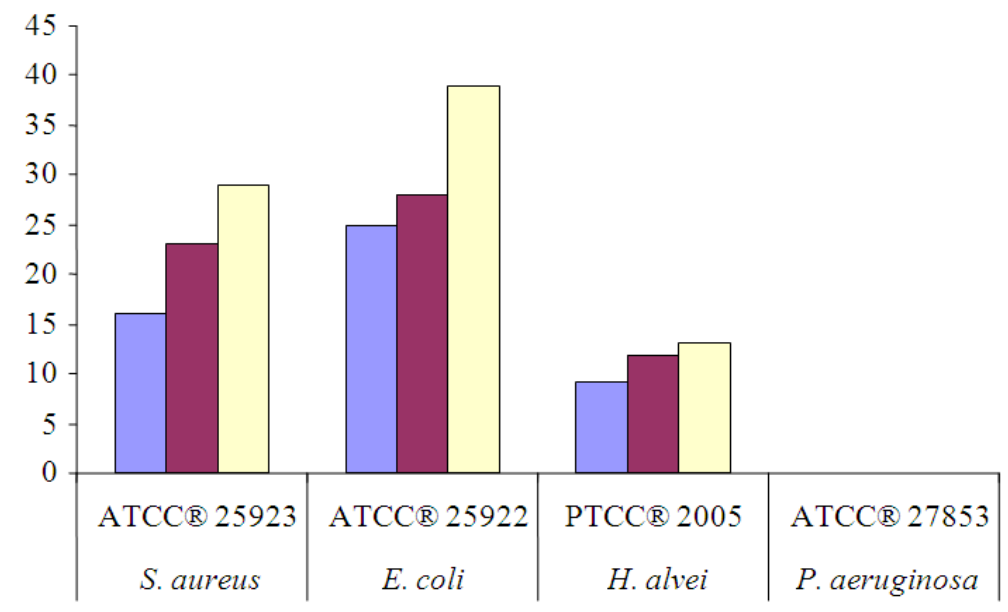

Fig. 3. Graphs of microbiological activity results for essential oil of J. communis (L.) growing wild in Kosova

Limonene (1.8\%) from Kosova J.communis $L$. essential oil, is in lower amount than in oil from Italy $(3.11 \%)^{10}$ and Serbia $(15.9 \%)^{11}$. Germacrene-D $(2.2 \%)$ in $J$. communis L. oil from Kosova is in same quantity as in essential oil from Estonia $(3.2 \%)^{12}$ but it is lower than in oil from Sicilia-Italy $(6.7 \%)^{11}$. The essential oil from Finland ${ }^{13}$ are dominated by $\alpha$-pinene (18-58\%), myrcene $(7-23 \%)$ and $\gamma$-cadinene $(5-13 \%)$. Our oil is in agreement with the essential oil of J. communis (L.) from Finland in the percentage of $\alpha$-pinene and myrcene but the oil from Finland contains more quantity of $\gamma$-cadinene than oil from Kosova $(0.7 \%)$.

The diameters of the inhibition zone of the essential oil of $J$. communis (L.) growing wild in Kosova, shown in Table 5, are presented also with graph (Fig. 3). From the results we saw that essential oil show antimicrobial activity against Staphylococcus aureus, Escherichia coli and Hafnia alvei. We found that if we increase the concentration of the essential oil, the diameter of inhibition zone will increase as we have expected. The essential oil of $J$. communis (L.) doesn't show any activity against the Pseudomonas aeruginosa.

\section{CONCLUSION}

The present work presents the chemical profile of the essential oil of Juniperus communis (L.) from east part of Kosova. The juniper berries oil from Kosova region contains more monoterpene $(83 \%)$ and less sesquiterpene (13.4\%). $\alpha$-pinene and myrcene were the major components of the monoterpene hydrocarbons. This study demonstrates the occurrence of $\alpha$-pinene chemotype of J. communis (L.) from east part of Kosova. Comparing our results with Juniperus communis (L.) oils from different parts of the Europa, it was evident that our oil is slightly different from the others regions on chemical profiles. After comparison of our date with those reported in literature ${ }^{6-13}$, we can conclude that genetic and environmental factors play role in chemical profiles of essential oil of Juniperus communis (L.) and the essential oil of J. communis (L.) growing wild in Kosova, showed moderate to high activities against Staphylococcus aureus, Escherichia coli and Hafnia alvei. Essential oil of J. communis (L.) is not active against Pseudomonas aeruginosa.

\section{ACNOWLEDGMENT}

The researchers acknowledge the financial support received from the University of Prishtina, Kosova.

\section{REFERENCES}

Adams, P.R., 2001. Identification of Essential Oil Components by Gas Chromatography/Quadrupole Mass Spectroscopy. 3rd Edn., Allured Pub. Corporation, Carol Stream, pp: 456.

Angioni, A., A. Barra, M.T. Russo, V.Coroneo and S. Dessi et al., 2003. Chemical composition of the essential oils of Juniperus from ripe and unripe berries and leaves and their antimicrobial activity. J. Agric. Food Chem., 51: 3073-3078. DOI: $10.1021 / \mathrm{jf026203j}$ 
Chatzopoulou, S.P. and S.T. Katsiotis, 1993a. Study of the essential oil from Juniperus communis "Berries" (Cones) growing wild in Greece. Planta Med., 59: 554-556. DOI: 10.1055/s-2006-959760

Chatzopoulou, P.S. and T.S. Katsiotis, 1993b. Chemical investigation of the leaf oil of Juniperus communis L. J. Essential Oil Res., 5: 603-607. DOI: 10.1080/10412905.1993.9698291

Haziri, A., N. Aliaga, M. Ismaili, S. Govori and O. Leci et al., 2010. Secondary metabolites in essential oil of Achillea millefolium (L.) growing wild in east part of Kosova. Am. J. Biochem. Biotechnol., 6: 32-34. DOI: 10.3844/ajbbsp.2010.32.34

Haziri, A., S. Govori, M. Ismaili, F. Faiku and I. Haziri, 2009. Essential oil of Tanacetum parthenium (L.) from east part of Kosova. Am. J. Biochem. Biotechnol., 5: 226-228. DOI: 10.3844/ajbbsp.2009.226.228

Kallio, H. and K. Junger-Mannermaa, 1989. Maritme influence on the volatile terpenes in the berries of different ecotypes of juniper (Juniperus communis L.) in Finland. J. Agric. Food Chem., 37: 10131016. DOI: $10.1021 /$ jf00088a043

Koukos, K.P. and K.I. Papadopoulou, 1997. Essential oil of Juniperus communis L. grown in north Greece: Variation of fruit oil yield and composition. J. Essential Oil Res., 9: 35-38. DOI: 10.1080/10412905.1997.9700711
Leung, A.Y. and S. Foster, 1996. Encyclopedia of Common Natural Ingredients Used in Food Drugs, and Cosmetics. 2nd Edn., Wiley, New York, ISBN10: 0471508268, pp: 649.

Maarse, H., 1991. Volatile compounds in Foods and Beverages. 1st Edn., CRC Press LLC, New York, ISBN-10: 0824783905, pp: 764.

Milojevic, S.Z., T.D. Stojanovic, R. Palic, M.L. Lazic and B.V. Veljkovic, 2008. Kinetics of distillation of essential oil from comminuted ripe juniper (Juniperus communis L.) berries. Biochem. Eng. J., 39: 547-553. DOI: 10.1016/j.bej.2007.10.017

Ochocka, R.J., M. Asztemborska, D.R. Zook, D. Sybilska and G. Perez et al., 1997. Enantiomers of monoterpenic hydrocarbons in essential oils from Juniperus communis. Phytochemistry, 44: 869-872. DOI: 10.10116/S0031-9422(96)00587-0

Orav, A., M. Koel, T. Kailas and M. Muurisepp, 2010. Comparative analysis of the composition of essential oils and supercritical carbon dioxide extracts from the berries and needles of Estonian juniper (Juniperus communis L.). Procedia Chem., 2: 161167. DOI: $10.1016 /$ j.proche.2009.12.023 